\title{
Yetişkin hastalarda üst gastrointestinal sistemde yabancı cisimlerin yönetimi: Retrospektif tek merkez deneyimi
}

\author{
Management of foreign bodies in upper gastrointestinal system in adult patients: A retrospective \\ single center experience
}

(D) Ferit ÇELIK, (D) Ali ŞENKAYA, (DD Nalan Gülşen ÜNAL, Seymur ASLANOV, (D) A. Ömer ÖZÜTEMIZ

Ege Üniversitesi Tip Fakültesi, Gastaroenteroloji Bilim Dall, Izmir

\begin{abstract}
Giriş ve Amaç: Gastrointestinal sistemde yabancı cisimler dünyada ve ülkemizde ciddi mortalite ve morbidite nedenidir. Genellikle endoskopi ile çoğu vakada tedavi sağlanır. Bu çalışmada amaç üst gastrointestinal sistemde yabancı cisimlerin klinik, epidemiyolojik karakteristiklerinin tanımlanması, yerleșim özelliklerinin belirlenmesi, yapılan endoskopik tedaviler ve sonuçlarının incelenmesidir. Gereç ve Yöntem: Calışma Ocak 2016-Aralık 2019 tarihleri arasında Gastroenteroloji Bilim Dalında üst gastrointestinal sistemde yabancı cisim nedeniyle endoskopi yapılan hastaları içermektedir. Yabancı cismin özelliği, lokalizasyonu, komplikasyon varlığ ve tedavi şekline hastalara ait özofagogastroduodenoskopi raporlarından ulaşılmıștır. Hastane elektronik veritabanı kullanılarak hastaların; yaş, cinsiyet, mental durumu, endoskopinin yapılma zamanı, semptomları, mortalite durumu ile ilgili bilgilere ulaşılmıştır. Bulgular: Çalışmadaki 43 hastanın 16'sı kadın (\%37.2), yas ortalaması 52.2 yıl (22-86) idi. Hastalarnn 16'sinda disfaji (\%45.7) en sık semptom olarak saptanmıştır. Yabancı cisimler en sık olarak; 29 hastada özofagusta (\%67.4) ve 8 hastada (\% 18.6) midede saptanmıştır. Endoskopi sirasinda saptanan yabancı cisimlerin 28'i gida (\%65.1), 6'sı metal (\%14) ve 9'u diğer (\%20.9) yapıda görülmüștür. En sık tercih edilen endoskopik tedavi hastaların 21 'inde fare dişli forseps (\%48.8) ile yabancı cisim çıkarılmasıdır. Hastaların 13'ünde komplikasyon gelișmiș olup (\%30.2), en sık komplikasyon olarak laserasyon saptanmıştır. Sonuç: Gastrointestinal sistemdeki yabancı cisimler genellikle cerrahi müdahale gerek $\neg$ tirmeyip, erken endoskopik müdahale, yutulan yabancı cismin tanı ve tedavisinde en sik kullanılan, güvenli ve etkili yöntemdir.
\end{abstract}

Anahtar kelimeler: Üst gastrointestinal sistem, yabancı cisim, endoskopik tedavi, komplikasyon

\section{GİRIŞ}

Gastrointestinal sistemde (GIS) yabancı cisimler (YC) dünyada ve ülkemizde ciddi mortalite ve morbidite nedenidir $(1,2)$. ABD'de yabancı cisimlerin yutulması nedeniyle yılda yaklaşı 1500 ölüm meydana gelmektedir (3). Insidansı net olarak bilinmemekle birlikte ABD'de 13/100000 civarındadır (4). Yabancı cisimlerin \%80'i veya daha fazlası kendiliğinden gastrointestinal traktustan geçebilmekle beraber, vakaların yaklaşık \%20'sinde yabancı cisimlerin endoskopik veya cerrahi müdahale ile çıkarılması gerekmektedir $(5,6)$. Genellikle endoskopi ile çoğu vakada tedavi sağlanırken sadece vakaların \% l'inden daha azında cerrahi tedavi gereklidir $(3,7)$.
Background and Aims: The presence of foreign bodies in the gastrointestinal system is the cause of serious mortality and morbidity around the world and in Turkey. Endoscopic treatment is provided in most cases. The aim of this study was to define the clinical and epidemiological characteristics of foreign bodies in the upper gastrointestinal system, determine its localization features, and examine the endoscopic treatments applied and their results. Materials and Methods: Patients who underwent endoscopy because of the presence of foreign bodies in their upper gastrointestinal system in the Department of Gastroenterology between January 2016 and December 2019 were included in this study. Data about the characteristics and localization of foreign bodies, presence of complications, and the treatment method used were obtained from the esophagogastroduodenoscopy reports of the patients. Age, gender, mental status, the time of endoscopy, symptoms, and mortality status of the patients were obtained from the hospital electronic database. Results: Of the 43 patients included in the study, 16 (37.2\%) were females, and the mean age of all patients was 52.2 years (22-86 years). Dysphagia was found to be the most common symptom and was seen in $16(45.7 \%)$ patients. The foreign bodies were most frequently detected in the esophagus ( $n=29$; $67.4 \%)$, followed by the stomach $(n=8 ; 18.6 \%)$. Of the foreign bodies detected during endoscopy, 28 (65.1\%) were identified as food, 6 (14\%) as metal, and $9(20.9 \%)$ had other structures. The most preferred treatment method was removing the foreign bodies using a rat tooth forceps ( $n=21 ; 48.8 \%)$. Complications developed in 13 (30.2\%) patients, and the most common was laceration. Conclusion: The presence of foreign bodies in the gastrointestinal system generally does not require any surgical intervention, but an early endoscopic examination is the most common, safe, and effective method for the diagnosis and treatment of the foreign bodies ingested.

Key words: Upper gastrointestinal system, foreign bodies, endoscopic treatment, complications

Etiyoloji, epidemiyolojik dağılım ve tedavi yönetimi merkezlere göre farklılık gösterebilir (3). Yabancı cisim yutulmasının büyük çoğunluğu çocukluk çağında görülür $(8,9)$. Erişkinlerde diş protezi kullananlarda damakta his kaybı sonucu, obezlerde ağıdaki lokmayı fazla çiğnemeden yutma nedeniyle meydana gelebilir. Ayrıca, kronik alkoliklerde, epilepsi hastalarında, psikiyatrik bozukluğu olanlarda ve mental retarde bireylerde sıklığı artmaktadır (10-15). Üst GIS'de YC'lere anatomik yapı nedeniyle en sık özefagusta daha sonra ise midede rastlanır (16). 
Tanıda; anamnez ve fizik muayenenin yanı sıra radyolojik görüntüleme ile endoskopik yöntemler yer alır. Hastalar semptomatik olabileceği gibi asemptomatik de olabilirler. En sık görülen semptomlar; odinofaji, boğulma hissi, kusma, disfaji, takılma hissi, kansız veya kanlı sekresyon artışıdır $(17,18)$. YC yutulmasinda tanı ve tedaviᄀde gecikme; perforasyon, obstrüksiyon gibi ciddi komplikasyonlara neden olabilmektedir. Ayrıca YC'nin büyüklüğü, şekli, endoskopiye kadar geçen süre, bulunduğu yer ve hastanın komorbiditesi komplikasyon riski ile ilişkilidir (19,20).

Bu çalışmada amaç üst GİS'de YC'lerin klinik, epidemiyolojik karakteristiklerinin tanımlanması, yerleşim özelliklerinin belirlenmesi, yapılan endoskopik tedaviler ve sonuçlarının incelenmesidir.

\section{GEREC ve YÖNTEM}

\section{Hasta Seçimi}

Bu çalışma; Ocak 2016-Aralık 2019 tarihleri arasında Ege Üniversitesi Tıp Fakültesi, Gastroenteroloji Bilim Dalında üst GIS'de YC nedeniyle endoskopi yapılan hastaların retrospektif tek merkezli irdelenmesini içermektedir. Hastalar, endocam sistemine 'yabancı cisim' yazılarak taranmıştır ve endoskopi raporlarına ulaşılmıştır. Çalışmaya 43 hasta dahil edilmiştir. Hastane elektronik veritabanı kullanılarak hastaların; yaş, cinsiyet, bilinen GIS hastalığı varlığı, mental durumu, endoskopinin yapılma zamanı, semptomları, mortalite durumu ile ilgili bilgilere ulaşılmıştır. Hastalardan 18 yaş altı olanlar ve bilgilerine tam ulaşlamayanlar ve endoskopi işlemini tolere edemeyenler çalışma dışı bırakılmıştır.

\section{Endoskopik Prosedür}

Endoskopik incelemeler, Olympus GIFHD 190 özofagogastroduodenoskop ile bir gastroenteroloji uzmanı veya onun nezaretinde gastroenteroloji yan dal asistanı tarafindan, endoskopi hemşiresi eşliğinde yapılmıştır. Hastalara ait özofagogastroduodenoskopi raporlarından YC'nin özelliği (metal, gıda, diğer), lokalizasyonu (hipofarinks, özofagus, mide, bulbus ve duodenum 2. segment), komplikasyon varlığı (ülser, perforasyon, abse ve laserasyon) ve tedavi şekli (forseps, fileli snare, basket snare ve tripot) olgu rapor formuna yazılmıştır.

\section{İstatistiksel Analiz}

Yaş değişkeninin normal dağılıma uygunluğu görsel (histogram) ve analitik yöntemlerle (Kolmogorov Smirnov testi) incelendi. Çalışmada toplanmış olan verilerden yaş değişkeni ortalama, ortanca, standart sapma, en büyük-en küçük değer, kategorik veriler ise oran, yüzde gibi tanımlayıcı yöntemlerle ifade edildi. Yaş değişkeninin gruplara göre karşılaştırılması için Student-t testi kullanıldı. Kategorik değişkenlerin gruplar arasındaki karşılaştırmaları için yerine göre Ki-kare ya da
Fisher testleri (hücrelerde gözlenen değerlerin Ki-kare testi varsayımlarını sağlamadığı durumda) kullanılarak yapıldı. P değerinin 0.05 'in altında olduğu değerler istatistiksel olarak anlamlı kabul edildi. Tüm istatistiksel analiz ve hesaplamalar için SPSS Statistics Ver. 22.0 programı kullanıldı.

\section{Etik Onam}

Çalışmada etik ilkelere uyulmuş ve çalışma için Ege Üniversitesi Tıbbi Araştırmalar Etik Kurulu 29.05.2020 tarih ve 205.1T/15 sayılı etik kurul onayı alınmıştır.

\section{BULGULAR}

Çalışmadaki toplam 43 hastanın 16'sı kadın (\%37.2), 27'si erkekti (\%62.8). Hastaların yaş ortalaması 52.2 yll (22-86) idi. Hastaların 35'inde semptom (\% 81.4) vardı. Hastaların 16'sında disfaji (\%45.7), 9'unda disfaji ile birlikte göğüs ağrısı (\%25.7), 5'inde takılma hissi (\% 14.3), üçünde epigastrik ağrı (\%8.5), birinde odinofaji (\%2.9) ve birinde kusma (\%2.9) şikayeti vardı. YC'li olguların 26'sına ilk 24 saat içinde (\%60.5), 17 'sine 24 saatten sonra (\%39.5) endoskopi yapılmıştır. Hastalarin 15'inde endoskopi esnasinda veya önceden tanısı olan GIS hastalığı mevcuttu (\%34.9). Bu hastaların 6'sında koroziv hasar (\%13.9), 3'ünde Schatzki halkası (\%6.9), 2'sinde web (\%4.7), 2'sinde gastrektomiye sekonder anastamoz darlığ (\%4.7), birinde skleroderma özofagus tutulumu (\%2.3), birinde özofagus kanseri (\%2.3) saptanmıştır. Hastaların demografik ve klinik özellikleri Tablo l'de özetlenmiştir.

Tablo 1. Hastaların demografik ve klinik özellikleri

\begin{tabular}{lc} 
Değişkenler & n (\%) \\
Yaş (ortalama \pm SD) & $52.2 \pm 2.6$ \\
\hline Cinsiyet & \\
Kadın & $16(37.2)$ \\
Erkek & $27(62.8)$ \\
Başvuru semptomları & \\
Disfaji & $16(45.7)$ \\
Disfaji+göğüs ağrısı & $9(25.7)$ \\
Takılma hissi & $5(14.3)$ \\
Epigastrik ağrı & $3(8.5)$ \\
Kusma & $1(2.9)$ \\
Odinofaji & $1(2.9)$ \\
Asemptomatik & $8(18.6)$ \\
Gís komorbiditesi & $15(34.8)$ \\
Koroziv hasar & $6(13.9)$ \\
Schatzki halkası & $3(6.9)$ \\
Web & $2(4.7)$ \\
Anastomoz darlı̆̆ & $2(4.7)$ \\
Skleroderma özofagus tutulumu & $1(2.3)$ \\
Özofagus kanseri & $1(2.3)$ \\
\hline
\end{tabular}

n: Hasta saylsı, SD: Standart deviasyon, GIS: Gastrointestinal sistem. 
YC'ler en sık 29 hastada özofagusta (\%67.4) ve 8 hastada midede (\%18.6) saptanmıştır. Endoskopi sırasında saptanan

Tablo 2. Yabancı cisimlerin türü, lokalizasyonu endoskopik tedavi ve komplikasyonları

\begin{tabular}{|c|c|}
\hline Değişkenler & n (\%) \\
\hline $\begin{array}{l}\text { Lokalizasyon } \\
\text { Özofagus } \\
\text { Mide } \\
\text { Duodenum 2. segment } \\
\text { Anastomoz hattı } \\
\text { Bulbus } \\
\text { Hipofarinks }\end{array}$ & $\begin{array}{c}29(67.4) \\
8(18.6) \\
2(4.7) \\
2(4.7) \\
1(2.3) \\
1(2.3)\end{array}$ \\
\hline $\begin{array}{l}\text { YC Türü } \\
\text { Gııa } \\
\text { Et } \\
\text { Kemikli et } \\
\text { Ekmek } \\
\text { Sarımsak } \\
\text { Balık kılçı̆̆ı } \\
\text { Elma } \\
\text { Metal } \\
\text { Iğne } \\
\text { Çivi } \\
\text { Diş implantı } \\
\text { Metal tel } \\
\text { Protez diş } \\
\text { Diğer* }\end{array}$ & $\begin{array}{c}28(65.1) \\
12(27.9) \\
7(16.4) \\
4(9.4) \\
3(6.9) \\
1(2.3) \\
1(2.3) \\
6(14) \\
2(4.7) \\
1(2.3) \\
1(2.3) \\
1(2.3) \\
1(2.3) \\
9(20.9)\end{array}$ \\
\hline $\begin{array}{l}\text { Uygulanan endoskopik tedavi } \\
\text { Fare dişli forseps } \\
\text { Fileli snare } \\
\text { Tripot forseps } \\
\text { Basket snare }\end{array}$ & $\begin{array}{c}42(97.7) \\
21(48.8) \\
18(41.9) \\
2(4.7) \\
1(2.3)\end{array}$ \\
\hline $\begin{array}{l}\text { Komplikasyon } \\
\text { Laserasyon } \\
\text { Ülser } \\
\text { Perforasyon+pnömotoraks }\end{array}$ & $\begin{array}{c}13(30.2) \\
10(23.2) \\
2(4.7) \\
1(2.3)\end{array}$ \\
\hline
\end{tabular}

n: Hasta sayısı, YC: Yabancı cisim, diğer*: Kürdan $(n=2)$, salivary bypass tüp $(\mathrm{n}=2)$, ilaç blisteri $(\mathrm{n}=1)$, sert plastik $(\mathrm{n}=1)$, kablo+çakmak+kimlik kartı $(\mathrm{n}=1)$, hap $(\mathrm{n}=1)$, silikon protez malzemesi $(\mathrm{n}=1)$.
YC'lerin 28'i gıda (\%65.1), 6'sı metal (\%14) ve 9'u diğer (\%20 .9) yapıdaki içeriklerdi. Gıda içeriğindeki yabancı cisimlerin 12'si et (\%27.9), 7'si kemikli et (\%16.4), 4'ü ekmek (\%9.4), 3'ü sarımsak (\%6.9), biri balık kılçığı (\%2.3) ve biri elmaydı (\%2.3). Metal içeriğindeki yabancı cisimlerin 2'si iğne (\%4.7), biri çivi (\%2.3), biri implant (\%2.3), biri keskin tel (\%2.3) ve biri protez dişti (\%2.3). Tespit edilen diğer yabancı cisimlerin 2'si kürdan (\%4.7) ve 2'si salivary bypass tüptü (\%4.7). Mental retarde üç olgumuzda ise çoklu yabancı cisim saptanmıştır. Yabancı cisimler bir olguda iki adet ilaç blisteri, bir olguda üç parça 30-20-15 mm çapinda sert plastik, bir olguda ise iki adet çakmak, bir adet sert kimlik kartı, bir adet kablo saptanmıştır. YC'lerin türü, GIS'deki lokalizasyonları, yapılan endoskopik tedavi ve komplikasyonlar Tablo 2'de gösterilmiştir. YC'lere ait örnek fotoğraflar Resim l'dedir.

Radyolojik görüntülemesi olan toplam 33 hastanın sadece 6'sında radyolojik görüntüleme yöntemi ile YC tespit edilmiştir (\%18.1). Endoskopik tedavi yöntemi uygulanan 42 hastanın, 2l'inde fare dişli forseps (\%48.8), 18'inde fileli snare (\%41.9), ikisinde tripod forseps (\%4.7), birinde basket snare (\%2.3) ile YC çıkarılmıştır. Hastaların 13'ünde komplikasyon gelişmiştir (\%30.2). Komplikasyon gelişen hastaların 10'unda laserasyon (\%23.2), ikisinde ülser (\%4.7) ve birinde hem perforasyon hem de pnömotoraks (\%2.3) görülmüștür. Perforasyon ve pnömotoraks gelişen bu hastaya tarafımızca metal kaphı özofagus stenti uygulandıktan sonra takip amaçlı genel cerrahiye devredilmiştir. Genel cerrahide takip edilen hastaya tüp torokostomi takılmış, 15 gün sonra hasta genel cerrahiden şifa ile taburcu edilmiştir. Hastalarımızda mortalite gelişmemiştir. Endoskopik tedavi ve komplikasyonları Tablo 2'de gösterilmiştir.

Hastalar semptomatik ve asemptomatik iki gruba ayrıldığında bu hastalar arasinda yabancı cisim tipi (gıda veya metal) ve altta yatan GIS hastalığı açısından anlamlı farklılık bulunmuştur (sirasiyla $\mathrm{p}<0.001$ ve $\mathrm{p}=0.036$ ). Semptomatik hastaların \%80'inde gıda impaksiyonu saptanmış ve bu semptomatik olguların \%42.9'unda endoskopide yeni saptanmış GIS hastalığ1 veya bilinen GIS hastalı̆̆ öyküsü rapor edilmiştir. Semptomatik ve asemptomatik hastaların demografik, klinik, radyolojik bulgularının karşılaştırılması Tablo 3'de özetlenmiştir.

Tablo 3. Semptomatik ve asemptomatik vakaların karşılaştırılması

\begin{tabular}{|c|c|c|c|}
\hline & Semptomatik n (\%) & Asemptomatik n (\%) & p değeri \\
\hline $\begin{array}{c}\text { YC türü } \\
\text { Gıda } \\
\text { Metal } \\
\text { Diğer }\end{array}$ & $\begin{array}{l}28(80) \\
3(8.6) \\
4(11.4)\end{array}$ & $\begin{array}{c}0(0) \\
3(37.5) \\
5(62.5)\end{array}$ & $<0.001$ \\
\hline $\begin{array}{l}\text { GİS komorbiditesi } \\
\text { Var } \\
\text { Yok }\end{array}$ & $\begin{array}{l}15(42.9) \\
20(57.1)\end{array}$ & $\begin{array}{c}0(0) \\
8(100)\end{array}$ & 0.036 \\
\hline
\end{tabular}

n: Hasta sayısı, YC: Yabancı cisim, GIS: Gastrointestinal sistem. 


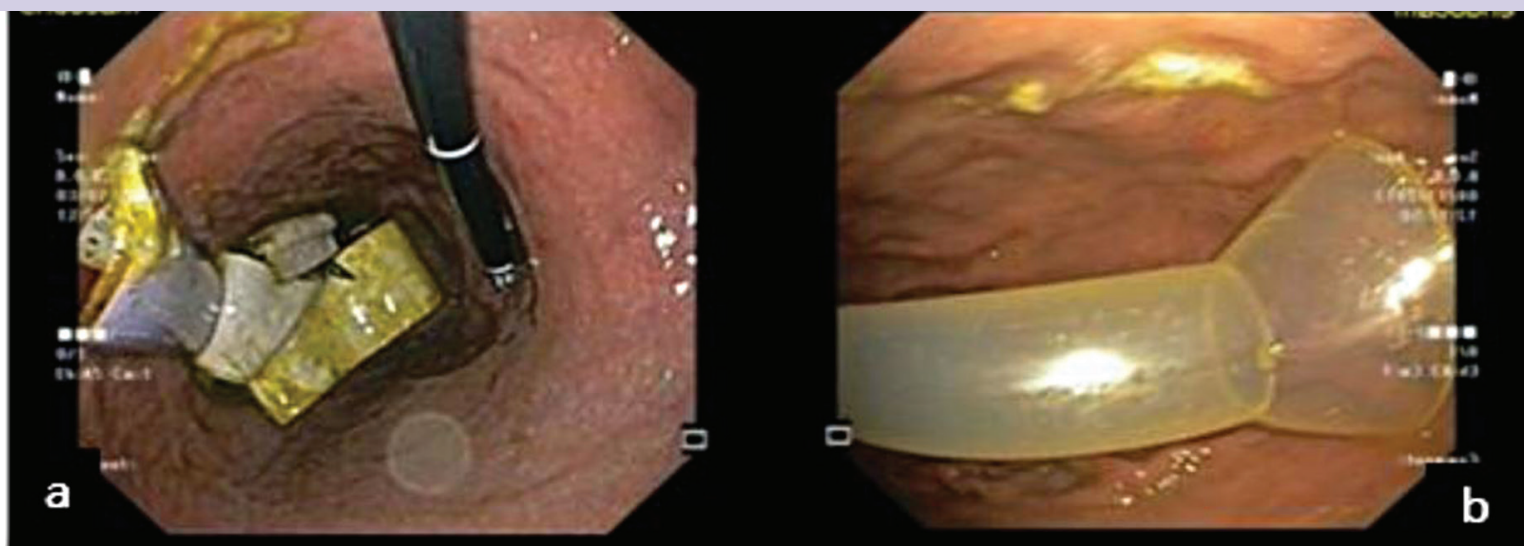

a. Midede 3 parça sert plastik

b. Midede salivary bypass tüp

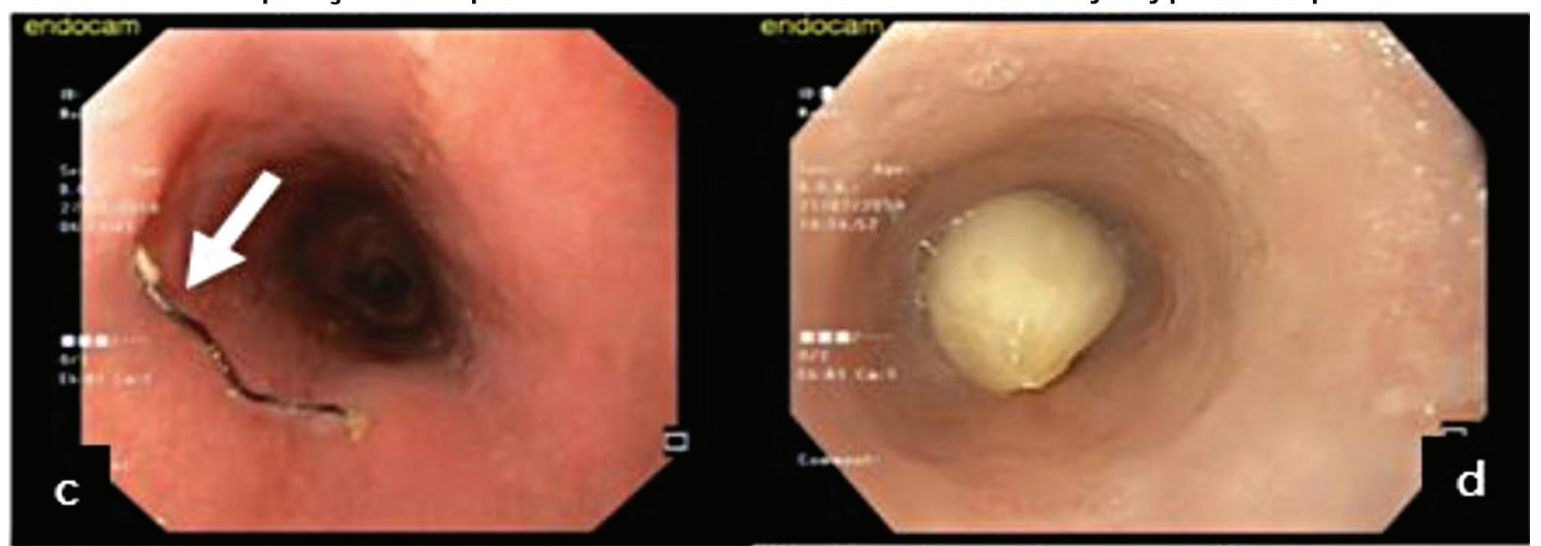

c. Özofagusta metal tel

d. Özofagusta sarımsak

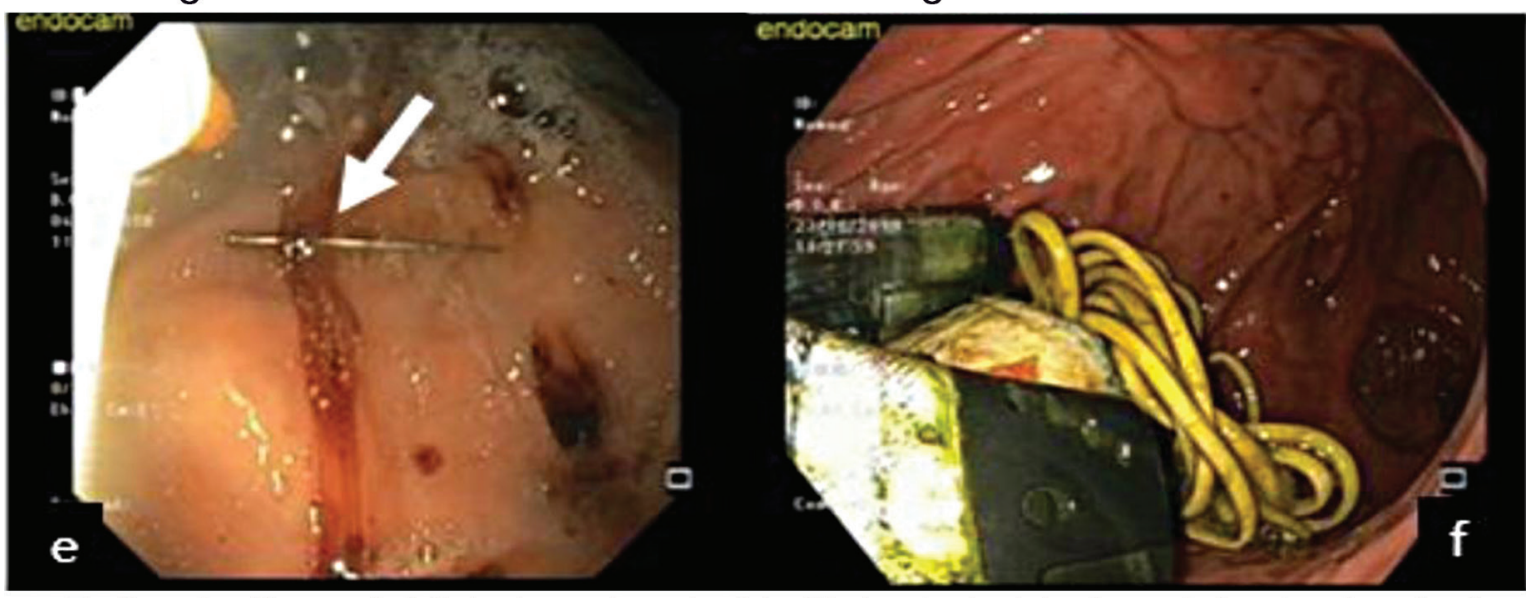

e. Bulbusta iğne f. Midede çakmak, kimlik kartı, kablo (mental retarde olgu)

Resim 1. Yabancı cisimlere ait örnekler

(Görüntüler Ege Üniversitesi Gastroenteroloji Bilim Dalı Endoskopi Ünitesi arşivinden alınmıştır.)

Tablo 4. Radyolojik bulgusu olan ve olmayan vakaların YC özelliklerinin karşılaştırılması

\begin{tabular}{|c|c|c|c|}
\hline & Radyolojik Bulgu Var n (\%) & Radyolojik Bulgu Yok n (\%) & p değeri \\
\hline $\begin{array}{c}\text { YC türü } \\
\text { Gıda } \\
\text { Metal } \\
\text { Diğer }\end{array}$ & $\begin{array}{c}1(16.7) \\
4(66.6) \\
1^{a}(16.7)\end{array}$ & $\begin{array}{c}21(77.8) \\
1(3.7) \\
5^{\mathrm{b}}(18.5)\end{array}$ & $<0.001$ \\
\hline
\end{tabular}

n: Hasta sayısı, YC: Yabancı cisim, ${ }^{a}$ : kablo+çakmak+kimlik kartı (n=1), b: kürdan (n=2), sert plastik (n=1), hap (n=1), silikon protez malzemesi $(n=1)$. 
Tablo 5. Komplikasyon görülen ve görülmeyen olguların demografik, klinik ve endoskopik özelliklerinin değerlendirilmesi

\begin{tabular}{|c|c|c|c|}
\hline Değişkenler & $\begin{array}{c}\text { Komplikasyon Görülen } \\
\text { n (\%) }\end{array}$ & $\begin{array}{c}\text { Komplikasyon Görülmeyen } \\
\text { n (\%) }\end{array}$ & p Değeri \\
\hline Yaş $($ mean $\pm S D)$ & $52.9 \pm 15.5$ & $51.9 \pm 18$ & 0.864 \\
\hline $\begin{array}{c}\text { Cinsiyet } \\
\text { Kadın } \\
\text { Erkek }\end{array}$ & $\begin{array}{l}4(30.8) \\
9(69.2)\end{array}$ & $\begin{array}{l}12(40) \\
18(60)\end{array}$ & 0.735 \\
\hline $\begin{array}{c}\text { YC türü } \\
\text { Gıda } \\
\text { Metal } \\
\text { Diğer }\end{array}$ & $\begin{array}{l}8(61.5) \\
2(15.4) \\
3(23.1)\end{array}$ & $\begin{array}{c}20(66.7) \\
4(13.3) \\
6(20)\end{array}$ & 0.949 \\
\hline $\begin{array}{l}\text { Semptom } \\
\text { Var } \\
\text { Yok }\end{array}$ & $\begin{array}{c}11(31.4) \\
2(25)\end{array}$ & $\begin{array}{c}24(68.6) \\
6(75)\end{array}$ & 1.000 \\
\hline $\begin{array}{l}\text { Endoskopi zamanı } \\
\text { Ilk } 24 \text { saat } \\
24 \text { saatten sonra }\end{array}$ & $\begin{array}{l}5(38.5) \\
8(61.5)\end{array}$ & $\begin{array}{l}21(70) \\
9(30)\end{array}$ & 0.052 \\
\hline $\begin{array}{l}\text { GIS komorbiditesi } \\
\text { Var } \\
\text { Yok }\end{array}$ & $\begin{array}{l}3(23.1) \\
10(76.9)\end{array}$ & $\begin{array}{l}12(40) \\
18(60)\end{array}$ & 0.487 \\
\hline
\end{tabular}

n: Hasta sayısı, SD: Standart deviasyon, YC: Yabancı cisim, GIS: Gastrointestinal sistem.

Radyolojik bulgusu olan ve olmayan vakalar arasında saptanan YC türüne göre istatistiksel olarak anlamlı fark saptanmiştır ( $\mathrm{p}<0.001)$. Radyolojik bulgusu olan hastaların 4'ünde metal yapida (\%66.7), radyolojik bulgusu olmayan vakaların 2l'inde gıda içeriğinde (\%77.8) YC görülmüştür. Radyolojik bulgusu olan ve olmayan vakaların YC özelliklerinin karşılaştırılması Tablo 4'de özetlenmiştir.

Komplikasyon olan ve olmayan vakalar arasında yaş, cinsiyet, yabancı cisim içeriği, semptom varlığı, endoskopi zaman1, endoskopide saptanan veya bilinen GIS hastalığı varlığ açısından istatiksel anlamlı farklılık saptanmamıştır (sırasıyla $\mathrm{p}=0.864,0.735,0.949,1.000,0.052,0.487$ ) (Tablo 5).

\section{TARTIȘMA}

YC yutulması ve gıda impaksiyonu günlük pratikte sıkça karşılaşılan bir durumdur. Üst GIS'de YC yutulması her yaşta görülebilmekle birlikte erişkin yaş grubunda daha nadir görülmesine rağmen, morbitide ve mortalite oranı daha yüksektir

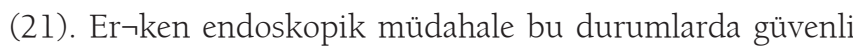
ve etkili bir tedavi yöntemidir. Tanı ve tedavi aşamasındaki gecikmeler çok ciddi komplikasyonlara yol açabil $\neg$ mektedir (21). Bu çalışma üst GIS'de YC yutulması ve gıda impaksiyonu saptanan 43 olguda endoskopik müdahale için en iyi zamanlamayı, uygun endoskopik yöntemleri ve gerekli araçları belirlemek için yapılmış retrospektif analizini içermektedir.
YC'ler en sık çocuk yaş grubunda görülmektedir ancak, erişkin yaş grubunda yapılan çalışmalarda, erişkinde yaş ortalaması 46.8-56 yıl arasında bildirilmiştir (22-25). Çalışmamızda da benzer şekilde erişkin yaş grubunda ortalama 52.2 (22-86) yıl olarak saptanmıştır. Yapılan çalışmalarda değişik oranlarda YC türleri bildirilmiştir, bunlar içerisinde en sık erişkin yas grubu içerisinde gıda impaksiyonu saptanmıştır $(24,25)$. Ülkemizde yapılan çalışmalarda da en sık \%42.268.8 ile gıda parçaları ilk sırayı almıştır $(1,23,26,27)$. Gıda parçaları içerisinde üç olgumuzda sarımsak yutulması dikkati çekmektedir. Hastalardan alınan anamnezde, geleneksel tedavi yöntemi olarak sarımsağın bütün yutulması ile daha faydalı olacağı inancı bu sonuca neden olmuştur. Çalışmamızda da literatüre benzer şekilde erişkin yaş grubunda gıda impaksiyonunun en sik neden olduğu görülmüştür. Bunun muhtemel nedenleri yaş birlikte altta yatan bir özofagus hastalığının eşlik etmesi, diş sağlığı probleminin ön plana çıkması ve eşlik eden psikiyatrik hastalık olabilir.

YC'nin çıkarılma ihtiyacı ve zamanı hastanın yaşına, klinik durumuna, yutulan cismin boyutuna, şekline, içeriğine, anatomik lokalizasyonuna ve yutulduktan sonra geçen süreye göre değişir (1,2,27-29). Literatürde GIS'deki tüm YC'lerin, tercihen 24 saat içinde çıkarılması önerilmektedir $(20,23,24,30,31)$. Çünkü basınç altında uzun süreli temas lokal nekroza yol açarak komplikasyon riskini artırabilir. 
YC'nin stridor gibi solunum semptomları ile prezente olmas1, daha yüksek pulmoner aspirasyon riski nedeniyle en kısa sürede çıkarılmasını gerektirir. Ayrıca toksik, sivri ve yetişkinlerde 10 cm'den uzun olduğu düşünülen YC'lerin tanıdan hemen sonra çıkarılması önerilir (32). Çalışmamızda da literatüre benzer şekilde \% $60.5^{\prime}$ ine ilk 24 saat içinde endoskopik işlem yapılmıştır. Yirmidört saatten sonra endoskopik işlem yapilmasının muhtemel nedenleri ise hastaların hastaneye geç başvurusu veya üçüncü basamak bir merkez olmamızdan dolayı hastaların dış merkezden sevkli olarak tarafımıza yönlendirilmesidir.

Literatürde daha önceden yapılan çalışmalarda üst GIS'de YC lokalizasyonu en sik \%28.9-89.2 ile özofagus olarak bildirilmiştir $(25,26,33)$. Çalışmamızda da benzer şekilde en sık lokalizasyon \%67.4 ile özofagus olarak saptanmıştır. Özofagusta daha fazla YC tespit etmemizin başlıca nedenleri, özofagusta yer alan anatomik darlıklar, sekonder özofagus hastalıklarının varlığı (koroziv striktür, schatzki halkası ve motilite kusurları), özofagustaki yabancı cisimlerin daha semptomatik olup hastanın hastaneye erken başvurması ve dolayısıyla acil endoskopi yapılması olarak düşünülmüştür. Ülkemizde Kefeli A. ve ark.'nın (27) yaptığı çalışmaya benzer şekilde, üç mental retarde (\%7) olgu saptanmıştır. Bu olgulardan birincisi iki adet ilaç blisteri yutup herhangi bir yakınma olmaksızın hasta yakınları tarafından hastaneye getirilmiş, yapılan endoskopide midede saptanan YC'ler başarılı bir şekilde ve komplikasyon olmadan çıkarılmıştır. Ikinci olgu ise üç parça 30-20-15 mm çapında sert plastik yutmuş, bulantı kusma nedeniyle hastanemize başvurmuş olup yapılan endoskopide midede YC'ler saptanmış ve endoskopi ile başarılı bir şekilde çıkarılmıştır. Üçüncü mental retarde olgumuz ise iki adet çakmak, bir adet sert kimlik kartı, bir adet kablo yutmuş olup hastaya yapılan endoskopi ile çıkarılamadığından genel cerrahiye devredilmiş, YC'ler cerrahi yöntem ile çıkarılmıştır. Bu olgu, endoskopik yöntem ile tedavi edilmeyen tek olgumuzdur.

Literatürde hastaların en sık hastaneye başvuru şikayeti disfajidir $(22,23,26)$. Çalışmamızda da hastalarda en sık semptom \%37.2 ile disfaji olarak saptanmıştır. Bunun muhtemel nedeni olgularımızın çoğunda YC veya gıda impaksiyonunun en sık özofagusta yerleşmesidir. Çalışmamızda ayrıca semtomatik olgular ile asemptomatik olguların karşılaştırılmasında semptomatik olgularda YC türü ve endoskopide saptanan veya bilinen GIS hastalığı açısından istastiksel olarak anlamlı fark saptanmıştır (sırasıyla $\mathrm{p}<0.001$ ve $\mathrm{p}=0.036$ ). Daha önceden semptomatik ve asemptomatik hastaları karşılaştıran bir çalışmada hipofarinks ve özofagusta saptanan YC'lerin anlamlı olarak semptomatik olduğu rapor edilmiştir (24). Çalışmamızdaki asemptomatik hastaların hepsinde (8 hasta) altta yatan GIS komorbiditesi bulunmamaktadır ve bu GIS komorbiditeleri özofagus lokalizasyonu göstermektedir. Bu, özellikle özofagus patolojilerinin YC impaksiyonuna sebep olarak, bu nedenle semptomatik seyretmesine sebep oldugunu göstermektedir. YC türü gıda olan hastaların hepsi (28 hasta \%80) semptomatik seyretmiş, diğerleri ise hem semptomatik hem de asemptomatik olmuştur. Bunun muhtemel nedeni gıdaların boyut ve şekil olarak impaksiyona sebep olma riskinin yüksek olması ve semptoma sebep olması, metal veya diğer yabancı cisimlerin ise iğne, çivi, metal tel gibi sivri özellikte olması nedeniyle bazen asemptomatik seyredebilmesi olabilir. Dolayısıyla gida türlü YC'lerin asemptomatik olma ihtimali çok düşük, fakat diğerlerinin asemptomatik olma durumu mevcut olup, hatta bu tür YC'lerin endoskopik olarak saptanma ihtimalinin azalmasına ve daha distal GIS segmentlerine ilerlemesine sebep olduğunu düşünmekteyiz.

Radyolojik bulgusu olan ve olmayan vakalar arasinda saptanan YC türüne göre istatistiksel olarak anlamlı fark saptanmıştır ( $<<0.001$ ). Radyolojik bulgusu olan hastaların 4'ünde metal yapida (\%66.7), radyolojik bulgusu olmayan vakaların 2l'inde gıda içeriğinde (\%77.8) YC görülmüştür. Bunun muhtemel sebebi, gıda türü ve metal dışı diğer YC'lerin radyoopak olmaması nedeniyle radyolojik olarak kolayca görülememsi, bu nedenle radyografik tetkiklerde saptanmamaları varlıklarını ekarte ettiremez olmasıdır (18). Bu sebepten, özofagus semptomları olan hastalar, negatif görüntülemeye rağmen endoskopik değerlendirmeye tabi tutulmalıdır.

Literatürde endoskopik yöntemler içerisinde en sik forseps tercih edilmiştir $(22,25)$. Çalışmamızda sırasıyla en sık tercih edilen yöntemler fare dişli forseps (\%48.8) ve fileli snare (\%41.9) olarak saptanmıştır. Tercih edilecek yöntemin yabancı cismin şekline ve hekimin teknik becerisine göre değissmekle birlikte, fare dişli forseps ve fileli snare'in YC'nin endoskopik tedavisinde ön planda uygulanması gerektiğini düşünmekteyiz.

Üst GIS'de YC'lerin neden olduğu komplikasyonların insidansı \%15-42'dir. Bunlar genellikle erozyonlar, yüzeysel laserasyonlar, ödem, hematom ve hafif solunum yolu komplikasyonları gibi sınırlı komplikasyonlardır. Perforasyon gibi şiddetli komplikasyon insidansı \%0.5-7.5 arasında değişmektedir $(32,34)$. YC'de genel mortalite oran $\% 0-3.5$ 'tir $(32,34)$. Hong KH. ve ark.'nın yaptığı bir çalışmada \%23.7 oranında komplikasyon bildirilmiş olup en sık komplikasyon laserasyon olarak saptanmıştır (25). Çalışmamızda mortalite saptanmamış olup, komplikasyon oranı literatüre benzer şekilde \%30.2 bulunmuştur, bu komplikasyonlar içerisinde en sık laserasyon tespit edilmiștir. Geng C. ve ark.'nın yaptı̆̆ bir çalışmada; 60 yaş üstü olmak, özofagusta lokalize YC, keskin yabancı cisim ve 24 saatten fazla bekletilen YC komplikasyon gelişimi için risk faktörleri olarak tanımlanmıştır (20). Çalışmamızda ise komplikasyon gelişimi için herhangi bir risk faktörü saptanmamıștır. Bunun muhtemel nedeni hasta popülasyonumuzun sınırlı olmasıdır. 
Sonuç olarak, çocuklarda daha sık olmasına rağmen, YC yutulması klinik pratikte erişkinlerde de görülmektedir. GIS'deki YC'ler genellikle cerrahi müdahale gerek`tirmeyip, erken endoskopik müdahale yutulan YC'nin tanı ve tedavisi için en sık kullanılan güvenli ve etkili yöntemdir. Endoskopik

\section{KAYNAKLAR}

1. Çobanoğlu U, Yalçınkaya 1. Esophageal foreign bodies: Analysis of 175 patients. Turkish J Thorac Cardiovasc Surg 2008;16:244-9.

2. Obinwa O, Cooper D, O'Riordan JM. Gastrointestinal Foreign Bodies. In: (Eds) Garbuzenko D. Actual Problems of Emergency Abdominal Surgery, Published: September 21st 2016, 2016;75-94.

3. Webb WA. Management of foreign bodies of the upper gastrointestinal tract: Update. Gastrointest Endosc 1995;41:39-51.

4. Longstreth GF, Longstreth KJ, Yao JF. Esophageal food impaction: epidemiology and therapy. A retrospective, observational study. Gastrointest Endosc 2001;53:193-8.

5. ASGE Standards of Practice Committee, Ikenberry SO, Jue TL, Anderson MA, et al. Management of ingested foreign bodies and food impactions. Gastrointest Endosc 2011;73:1085-91.

6. Mosca S, Manes G, Martino R, et al. Endoscopic management of foreign bodies in the upper gastrointestinal tract: report on a series of 414 adult patients. Endoscopy 2001;33:692-6.

7. Schwartz GF, Polsky HS. Ingested foreign bodies of the gastrointestinal tract. Am Surg 1976;42:236-8.

8. Dray X, Cattan P. Foreign bodies and caustic lesions. Best Pract Res Clin Gastroenterol 2013;27:679-89.

9. Pfau PR. Removal and management of esophageal foreign bodies. Tech Gastrointest Endosc 2014;16:32-9.

10. Kamal I, Thompson J, Paquette DM. The hazards of vinyl glove ingestion in the mentally retarded patient with pica: new implications for surgical management. Can J Surg 1999;42:201-4.

11. Palta R, Sahota A, Bemarki A, et al. Foreign-body ingestion: characteristics and outcomes in a lower socioeconomic population with predominantly intentional ingestion. Gastrointest Endosc 2009;69:426-33.

12. O'Sullivan ST, Reardon CM, McGreal GT, at al. Deliberate ingestion of foreign bodies by institutionalised psychiatric hospital patients and prison inmates. Ir J Med Sci 1996;165:294-6.

13. Blaho KE, Merigian KS, Winbery SL, et al. Foreign body ingestions in the emergency department: case reports and review of treatment. J Emerg Med 1998;16:21-6.

14. Abdullah BJ, Teong LK, Mahadevan J, et al. Dental prosthesis ingested and impacted in the esophagus and orolaryngopharynx. J Otolaryngol 1998;27:190-4.

15. Craig RM, Vanagunas AD. Foreign bodies in the eosophagus. In: Shields TW (Eds). General thoracic surgery. Philadelphia: Lippincott Williams \& Wilkins; 2000;1763-7.

16. Smith MT, Wong RK. Esophageal foreign bodies: types and techniques for removal. Curr Treat Options Gastroenterol 2006;9:75-84.

17. Diaconescu S, Gimiga N, Sarbu I, et al. Foreign bodies ingestion in children: experience of 61 cases in a pediatric gastroenterology unit from Romania. Gastroenterol Res Pract 2016;62;1-6. yöntemler içerisinde forseps ve fileli snare ile yabancı cismin çıkarılması ön plana çıkmaktadır. Nadir de olsa klinik gereklilik halinde cerrahi tedavi akılda tutulmalıdır.

\section{"Tüm yazarlar herhangi bir çıkar çatışması olmadı̆̆ını be- yan ederler."}

18. Guelfguat M, Kaplinskiy V, Reddy $\mathrm{SH}$, et al. Clinical guidelines for imaging and reporting ingested foreign bodies. Am J Roentgenol 2014;203:37-53.

19. Eisen GM, Baron TH, Dominitz JA, et al. Guideline for the management of ingested foreign bodies. Gastrointest Endosc 2002;55:802-6.

20. Geng C, Li X, Luo R, et al. Endoscopic management of foreign bodies in the upper gastrointestinal tract: a retrospective study of 1294 cases. Scand J Gastroenterol 2017;52:1286-91.

21. Birk M, Bauerfeind P, Deprez PH, et al. Removal of foreign bodies in the upper gastrointestinal tract in adults: European Society of Gastrointestinal Endoscopy (ESGE) Clinical Guideline. Endoscopy 2016;48:489-96.

22. Chaves DM, Ishioka S, Felix VN, et al. Removal of a foreign body from the upper gastrointestinal tract with a flexible endoscope: a prospective study. Endoscopy 2004;36: 887-92.

23. Okan I, Akbaş A, Küpeli M, et al. Management of foreign body ingestion and food impaction in adults: A cross-sectional study. Ulus Travma Acil Cerrahi Derg 2019;25:159-66.

24. Lee CY, Kao BZ, Wu CS, et al. Retrospective analysis of endoscopic management of foreign bodies in the upper gastrointestinal tract of adults. J Chin Med Assoc 2019;82:105-9.

25. Hong KH, Kim YJ, Kim JH, et al. Risk factors for complications associated with upper gastrointestinal foreign bodies. World J Gastroenterol 2015;21:8125-31.

26. Ustaoğlu M, Paköz ZB. Üst gastrointestinal yabancı cisimlerinin analizi. KÜ Tip Fak Derg 2020;22:1-6.

27. Kefeli A, Başyigit S, Yeniova AÖ, et al. Üst gastrointestinal sistem yabanc1 cisimleri. Dicle Med J 2014;41:195-8.

28. Chen Q, Huang Y, Wuet Y, et al. A comparative study of small intestinal perforation secondary to foreign body and other non-traumatic causes. Ulus Travma Acil Cerrahi Derg 2015;21:107-12.

29. Tseng HJ, Hanna TN, Shuaib W, et al. Imaging foreign bodies: Ingested, aspirated, and inserted. Ann Emerg Med 2015;66:570-82.

30. Brady PG. Management of esophageal and gastric foreign body. In: Dimarino AJ, Benjamin SB (eds.) Gastrointestinal disease: an endoscopic approach. London; Blackwell Science 1997:407-17.

31. Ginsberg GG. Management of ingested foreign objects and food bolus impactions. Gastrointest Endosc. 1995; 41:33-8.

32. Vizcarrondo FJ, Brady PG, Nord HJ. Foreign bodies of the upper gastrointestinal tract. Gastrointest Endosc 1983;29:208-10.

33. Kafadar H, Kafadar S. Gastrointestinal yabancı cisim olgularının incelenmesi. Adıyaman Üni. Sağlik Bilimleri Derg 2019;5:1620-7.

34. Roura J, Morello A, Comas J, et al. Esophageal foreign bodies in adults. J Otorhinolaryngol 1990;52:51-6. 